time. Biopsies were analysed for neutrophil (neutrophil elastase) and macrophage (CD163) density using immunohistochemistry. ELISA measurements of inflammatory cytokines (IL-6 and TNF $\alpha$ ) were performed on blood samples.

Results Quadriceps strength increased by 7.6\% ( $p=0.024)$, thigh mass by $2.8 \%(\mathrm{p}=0.185)$, and quadriceps thickness by $11 \%(p=0.002)$. Muscle biopsies for 11 patients were analysed. Neutrophil density $24 \mathrm{~h}$ after a single bout of unilateral NMES significantly increased in both the trained and untrained limb, with larger increase in the stimulated muscle (Table 1). Neutrophil density returned to baseline in the trained limb following training. No changes were seen in muscle macrophage density, serum IL-6 or serum TNF $\alpha$.

Abstract P18 Table 1 Cellular inflammation in vastus lateralis biopsies following unilateral NMES in both trained and untrained limbs at baseline, 24 hours following first stimulation and 24 hours following 6 weeks training. Data are mean \pm SD

\begin{tabular}{llll}
\hline & Baseline & $24 \mathrm{~h}$ & 6 weeks \\
\hline $\begin{array}{l}\text { Neutrophil (Neutrophils } / \mathrm{mm}^{2} \text { ) } \\
\text { Trained Leg }\end{array}$ & $3.48 \pm 0.87$ & $33.40 \pm 11.65^{*}$ & $1.57 \pm 0.49^{* *}$ \\
$\begin{array}{l}\text { Neutrophil (Neutrophils } / \mathrm{mm}^{2} \text { ) } \\
\text { Untrained Leg }\end{array}$ & $1.27 \pm 1.36$ & $13.10 \pm 9.02^{*}$ & $10.97 \pm 12.92$ \\
$\begin{array}{l}\text { Macrophage (Neutrophils } / \mathrm{mm}^{2} \text { ) } \\
\text { Trained Leg }\end{array}$ & $4.87 \pm 6.74$ & $0.74 \pm 1.41$ & $4.22 \pm 10.58$ \\
$\begin{array}{l}\text { Macrophage (Neutrophils } / \mathrm{mm}^{2} \text { ) } \\
\text { Untrained Leg }\end{array}$ & $0.78 \pm 1.39$ & $8.02 \pm 9.03$ & $3.83 \pm 5.59$ \\
\hline *p-value $<0.05$ compared with baseline, **p-value $<0.05$ compared with $24 \mathrm{~h}$.
\end{tabular}

Conclusion A single bout of unilateral NMES provokes an intramuscular neutrophilic inflammatory response in both the trained and untrained limb, which are not mediated by changes in circulating IL-6 or TNF $\alpha$. Neutrophil infiltration returned to baseline in the stimulated leg following training.

\section{P19 PREDICTORS OF COPD MORTALITY, 2 YEAR FOLLOW-UP DATA FROM THE ARCADE STUDY}

${ }^{1} \mathrm{NS}$ Gale, ${ }^{1} \mathrm{~A}$ Albarrati, ${ }^{1} \mathrm{MM}$ Munnery, ${ }^{2} \mathrm{R}$ Tal-Singer, ${ }^{1} \mathrm{JR}$ Cockcroft, ${ }^{1} \mathrm{DJ}$ Shale. ${ }^{1}$ Cardiff University, Cardiff, UK; ${ }^{2} G S K$ R\&D, Pennsylvania, USA

\subsection{6/thoraxjnl-2015-207770.156}

Background COPD is a systemic disease with associated comorbidities including cardiovascular disease which have significant impact on morbidity and mortality. ${ }^{1}$ However, the progression of the disease is not well understood as there are few longitudinal studies of sufficient duration which include outcome data. The aim of this analysis was to evaluate predictors of mortality from the Assessment of Risk in Chronic Airways Disease Evaluation Study (ARCADE), Clinical Trials registration: NCT01656421. ${ }^{2}$

Methods The ARCADE study is a longitudinal observational study of cardiovascular risk and other comorbidities in patients with COPD. Patients were assessed at recruitment and after 2 years including the following outcomes: Spirometry, BMI, St Georges Respiratory Questionnaire (SGRQ), mMRC breathlessness, number of exacerbations and 6 min walk distance (6MWD). A sample of blood was analysed for the inflammatory mediator fibrinogen.

Results At baseline 524 patients with COPD, confirmed with spirometry, were recruited to the study. Thus far, at the 2 year follow up there have been 47 deaths. According to hospital records, causes of death were: respiratory $\mathrm{n}=22$ (including acute exacerbations/respiratory infections $(\mathrm{n}=12)$ and pneumonia $(\mathrm{n}=10))$, cardiovascular $\mathrm{n}=9$, cancer $\mathrm{n}=10$, septicaemia $\mathrm{n}=3$ and unknown $\mathrm{n}=4$.

At baseline the subjects who did not survive were similar to survivors in age, gender and BMI, but had greater airflow limitation, worse SGRQ, more breathlessness, more exacerbations and lower 6MWD, fibrinogen was also higher (Table 1). Using logistic regression of the objective markers which differed between the groups; FEV1\% predicted, number of exacerbations, 6MWD and fibrinogen were entered into the model. Of these Fibrinogen $(\mathrm{p}=0.013)$ and $6 \mathrm{MWD}(\mathrm{p}=0.024)$ were significant predictors of mortality $(\mathrm{X} 2(4)=18.678, \mathrm{p}=0.001)$.

\begin{tabular}{llll} 
Abstract P19 Table 1 & \multicolumn{3}{l}{ Baseline characteristics of patients } \\
\hline & Survivor & Non-survivor & $\mathrm{p}=$ \\
& $\mathrm{n}=477$ & $\mathrm{n}=47$ & \\
\hline Gender (male:female) & $246: 231$ & $27: 20$ & 0.294 \\
Age (years) & $66.0 \pm 7.6$ & $67.9 \pm 6.6$ & 0.098 \\
BMI (kg/m $\left.{ }^{2}\right)$ & $28 \pm 6$ & $27 \pm 5$ & 0.401 \\
FEV $_{1} /$ FVC (L) & $0.53 \pm 0.11$ & $0.49 \pm 0.12$ & 0.005 \\
FEV $_{1} \%$ predicted & $59 \pm 19$ & $52 \pm 19$ & 0.023 \\
Smoking pack years & $40 \pm 24.9$ & $45 \pm 29$ & 0.078 \\
SGRQ & $51 \pm 2$ & $58 \pm 18$ & 0.022 \\
mMRC breathlessness & $2(1-3)$ & $3(1-3)$ & 0.002 \\
No. Exac per year & $2(1-3)$ & $2.5(1.5-4)$ & 0.022 \\
6MWD (m) & $340 \pm 124$ & $273 \pm 114$ & 0.001 \\
Fibrinogen (g/L) & $3.6 \pm 1.0$ & $4.1 \pm 1.3$ & 0.002 \\
\hline Data expressed as mean \pm SD or median (range). & &
\end{tabular}

Conclusions The follow up mortality rate was 9\%, with the majority of deaths due to respiratory causes, followed by cancer and cardiovascular events. The non-survivors had poorer objective and patient reported outcomes. Further follow-up of this cohort will provide greater power to predict outcomes.

Thanks to all our volunteers and GlaxoSmithKline who funded the study.

\section{REFERENCES}

1 Mannino DM, Thorn D, Swensen A, Holguin F. Prevalence and outcomes of diabetes, hypertension and cardiovascular disease in COPD. Eur Respir J. 2008;32:962-69

2 Gale NS, Albarrati AM, Munnery MM, et al. Assessment of Risk in Chronic Airways Disease Evaluation (ARCADE): Protocol and preliminary data. Chron Respir Dis. 2014;11(4):199-207 